\title{
INDEX FOR VOLUME 15
}

Journal of Direct, Data and Digital Marketing Practice (2014) 15, 365. doi:10.1057/dddmp.2014.35

The Editors and Editorial Board of The Journal of Direct, Data and Digital Marketing Practice wish to acknowledge the assistance of our colleagues who reviewed articles for Volume 15, and for their contributions of time and experience. Without their dedication, our work in publishing this journal could not go forward.

Papers

Social network influences on young tourists: An exploratory analysis of determinants of the purchasing intention

Customers' online shopping preferences in mass customization

New influentials: An exploratory study on blogs

Consumer acceptance of mobile marketing communications using the QR code

Research in a world without questions

Demographic differences in recall and recognition rates of in-game advertisements

Imputing unknown competitor marketing activity with a Hidden Markov Chain

eWOM in online customer support communities: Key variables in information quality and source credibility

Towards practical relevance - Delivering superior firm performance through digital customer experience strategies

Mapping customer journeys in multichannel decision-making

Personality types and Facebook advertising: An exploratory study

\section{Opinion Pieces}

Co-operation between academics and practitioners - hope for the future?

Ethical marketing research in the digital age — How can academics and practitioners work together?

The marketing data space race

Customer experience in the omni-channel world and the challenges and opportunities this presents

Marketing in a mobile-first world: Tackling the why and the how

The consumer data revolution: The reshaping of industry competition and a new perspective on privacy

Monitoring mobile app performance

Apple iBeacon technology briefing

\section{Case Studies}

Adopting a new brand language at Cisco

IDM Student Competition 2013: English Wine Week

Piano Media profi les visitors and drives conversion

Barilla goes mobile with Ringo

Decca tests contextual mobile marketing

\section{Business Intelligence}

DMA print tracking: Attributes of media channels

The 2013 Customer Intimacy Index

Highlights from the 2013 Abacus Annual Trends Report

AOP content and trends Census 2013

fast.MAP Marketing-GAP research - IDM-sponsored questions

The insider threat to data assets

DMA Customer Acquisition Barometer 2014

Retail showrooms, mobile sales

\section{Reviews}

Fresh faces and business cases: The 10th IDM B2B marketing conference

Figaro digital marketing - Conference review

IDM Data Council open data discussion

DataIQ Future Summit 2013 - Conference Reviews

Open Data Institute/Institute of Direct and Digital Marketing joint event

MRS conference review: Tracking a decade of changing Britain

Brand vandals: Reputation wreckers and how to build better defences

Data smart: Using data science to transform information into insight

Future Foundation conference - Big data and the future of insight

IDM data council discussion - Organizing for data and analytics

Customer analytics and insights in retail fi nancial services
Author

di Pietro and Pantano

Isuue Page

Aichner and Coletti

Zanette, Brito and Coutinho

Ryu and Murdock

Ewing and Pankauskas

Toh and Leng

Haughton, Hua, Jin,

Lin, Wei and Zhang

Hannah, Filieri and Grundy

Klaus

14

Wolny and Charoensuksai

Clark and Çallı

120

136

Stone

Clark

Shaw

Cook

Save

Becker

Salz

Newman

Reed

Reed

Reed

Pazzagli

Sear

Jain and Reed

Wood

Masnaghetti

Cain

Reed

Galdies

Jain and Colwell

Willmott

Hellier

Reed

Reed

Reed

Leventhal

Webber

Reed

Reed

Reed

Reed
56 